\title{
Motivation for Cambodian Students Aspiring to Become Nurses
}

\section{Nozomi Nakajima ${ }^{1^{*}}$, Hiroko Shimizu ${ }^{{ }^{*}}$ and Hoshina Uehara ${ }^{2}$}

${ }^{1}$ Master Program of Nursing Science, Graduate School of Medicine, Kagawa University, Japan

${ }^{2}$ Department of Chronic Adult Nursing, Academic Group of Life Sciences, Kagawa University, Japan

\section{Abstract}

Objective: This study examines the reasons for nursing students to choose nursing as a career in Cambodia. Cross-sectional quantitative web-based questionnaire survey was used to collect data (English and Khmer versions, anonymous, five-item descriptive questionnaire). The participants were undergraduate nursing students [ $\mathrm{n}=33$ (20 \pm 3.2 years); males: 11, females: 22] at the National University of Cambodia. Questionnaire items included age, sex, "Why did you decide to become a nurse?" "What influenced you the most to become a nurse?" and "What is your goal after graduation?"

Methods: Data in English and Khmer were translated into Japanese using Google Translate, and content analysis was conducted according to the methodology of Berelson, B. The criterion of analysis was compared with the study findings of Ichiyanagi [1].

Results: In comparison with Japanese students who were mainly motivated "to help others," the most common motivation for Cambodian students was "to help the country." In both countries, the target of the motivation to be "helpful" was different. Additionally, $75 \%$ of the students answered "family" when asked about the factors that influenced their motivation. Furthermore, regarding the goals of Cambodian nursing students after graduation, many of them answered "I want to continue my studies to develop the nursing field."

Conclusion: This study examined motivation for Cambodian students aspiring to become nurses as a career. As a result of combining similar contents, the categories were divided into six each. Cambodian nursing students were motivated to help their country, protect their families and develop nursing care.

\section{Publication History:}

Received: September 09, 2021

Accepted: October 11, 2021

Published: Octobe 13, 2021

\section{Keywords:}

Cambodia, Behavior Rating Scale, Nursing, Asian Continental Ancestry Group

\section{Background}

Cambodia is a constitutional monarchy located in the southern part of the Indochina Peninsula in Southeast Asia. According to the International Monetary Fund, Cambodia has a population of approximately 15.83 million [2]. Cambodia has been invaded by neighboring countries, including Thailand and Vietnam, since the $14^{\text {th }}$ century and was placed under the French protectorate in 1863 [3]. In 1953, the country gained independence from France, and in 1975, the Khmer Rouge, an armed force led by Pol Pot, established the Democratic Cambodia (Pol Pot) regime [4]. During the 4-year Pol Pot regime, citizens living in Phnom Penh, the capital of Cambodia, were sent to forced mass camps in rural areas, and intellectuals, including doctors, nurses, and teachers, who could have been opposition forces were massacred $[5,6]$. The above shows that Cambodia has been unstable for many years because of conflicts with neighboring countries and domestic disputes.

Moreover, the massacre of intellectuals by the Pol Pot regime led to the temporary collapse of education in the country. As a result, as of $2021,50 \%$ of the population is under the age of 22 , and the number of young people who are unable to receive an appropriate education has been thought to increase [7].

After the signing of the Paris Peace Agreements in 1991, the political situation in Cambodia underwent a major transformation with the election of the Constituent Assembly and the enactment of the Constitution in 1993. The growth rate of gross domestic product was $1.1 \%$ in 1990; however, it gradually increased thereafter and continued to exceed $10 \%$ for 4 years from 2004 to 2007, and the economy rapidly grew [2,4]. In the Constitution adopted in 1993, Articles 36 and 72 of the Constitution guaranteed the freedom of choice of occupation and the health of the people, respectively [8].
However, Cambodia does not have a universal healthcare system, and medical expenses are basically self-financed [9]. The poverty rate in Cambodia has been decreasing yearly; it was $34 \%$ in 2008 and $17.7 \%$ in 2012 . However, the poverty rate between urban and rural areas was $15.1 \%$ and $38.5 \%$, respectively, in 2008 and $6.4 \%$ and $20.8 \%$, respectively, in 2012; hence, the poverty rate in rural areas is higher than that in urban areas [6]. Since $80 \%$ of the population lives in rural areas, many people living in rural areas were thought to bear the burden of medical expenses [5]. Although the constitution promises to protect the health of the people, the policy for health services remains inadequate.

The monthly salary of a professional nurse working in a public medical institution in Cambodia is $\$ 79$, respectively [10]. The monthly household expenditure in Cambodia is about $\$ 446$ per household and \$111 per person [11]. The amount of household expenditure exceeds the nurses' salary, and it is difficult for them to make a living. Therefore, nurses often work at both public and private medical institutions and clinics [7].

"Corresponding Author: Nozomi Nakajima, School of Nursing, Faculty of Medicine, Kagawa University, 1750-1 Ikenobe, Miki-cho, Kita-gun, Kagawa, 761 0793, Japan, Tel/Fax:+81-87-891-2240; E-mail: s21g703@kagawa-u.ac.jp

"Corresponding Author: Prof. Hiroko Shimizu, School of Nursing, Faculty of Medicine, Kagawa University, 1750-1 Ikenobe, Miki-cho, Kita-gun,Kagawa, 7610793, Japan, Tel/Fax:+81-87-891-2240; E-mail: shimizu.hiroko@kagawa-u.ac.jp

Citation: Nakajima N, Shimizu H, Uehara H (2021) Motivation for Cambodian Students Aspiring to Become Nurses. Int J Nurs Clin Pract 8: 347. doi: https://doi. org/10.15344/2394-4978/2021/347

Copyright: (C) 2021 Nakajima et al. This is an open-access article distributed under the terms of the Creative Commons Attribution License, which permits unrestricted use, distribution, and reproduction in any medium, provided the original author and source are credited. 
The study of Tukada et al. [12] on nursing students in the current nursing education identified three issues. First, the nursing students do not fully understand their studies or what they are learning. This is because the latest information on nursing is written in English, making understanding difficult for students who only know the local language. Second, educational materials and equipment are lacking. The number of students in a class is too large to be provided with all the educational materials and equipment; hence, alternative materials are used. Third, teachers cannot provide detailed guidance to all students. The number of students is increasing in relation to the number of teachers, and teachers cannot fully grasp the depth of understanding and difficulties the students are experiencing. The above problems are thought to have been caused by the collapse of education because of the civil war in the past, and the delay in education is believed to be a factor delaying the development of nursing science.

As noted above, the national policy, salary for nurses, and educational system for nursing students in Cambodia are lacking. Nevertheless, Kawakami, Utsunomiya, and Nakajima in their 2019 Student Support Project on Nursing Schools in Cambodia [13] have reported that "students attending a national university in Cambodia aspire to become nurses not only for themselves but also on behalf of their families and villages." Although Cambodia has many problems, students were thought to have strong aspirations and goals to become nurses. Kamekawa [14] stated that "motivation is a general term for the psychological energy that arises when people set some goals and take action to achieve them," and it is perceived that "motivation" exists when Cambodian nursing students aspire to become nurses. Furthermore, Kamekawa [14] stated that "in order for actions related to the attainment of some goal to function sustainably and effectively, not only the ability to carry out the action but also the motive that serves as the driving force are essential." Therefore, for Cambodian nursing students to become nurses and function sustainably and effectively in their work, examining their motives is necessary. Furthermore, by examining their motives, it is thought that it can be a material to connect to "motivation" that promotes the process of the emergence of motive.

\section{Research Objectives}

This study aimed to examine the motivation of Cambodian nursing students to become nurses.

\section{Research Method}

\section{Research design}

This study is a quantitative web-based questionnaire study.

\section{Target population}

The study participants included undergraduate nursing students [ $n=33$ (20 \pm 3.2 years); males: 11 , females: 22 ] enrolled in the National University of Cambodia as of August 2020.

To position the survey as a verification process of the contents reported in the 2019 Student Support Project Outcome Report, the survey targets included those belonging to the universities covered in the previous report. Snowball sampling was performed, without limiting age and gender, and the researchers requested for nursing students who had access to the Internet.
As a survey procedure, the co-researcher contacted the international office of the university to which the subject belonged to, and the survey was conducted with the approval of the university president. The university president informed and explained the survey to the faculty member in charge of international exchange in the nursing department, and faculty member supported for the survey of the nursing students.

\section{Data collection method}

Data were collected through a cross-sectional web-based questionnaire survey (English and Khmer versions, anonymous, fiveitem descriptive questionnaire).

\section{Preparation of survey items}

The questionnaire items were from the study of Sakurai et al. [15]. The measurement scale has six perspectives: (a) challenge, (b) curiosity, (c) mastery, (d) perceived locus of causality, (e) endogenousexogenous attribution, and (f) enjoyment. These items were designed to measure intrinsic motivation. Items (a) challenge, (b) curiosity, (c) mastery, and (f) enjoyment were measured to determine intrinsic motivation, whereas items (d) perceived locus of causality and (e) endogenous-exogenous attribution were measured to distinguish between intrinsic and extrinsic motivation; the concept of this perspective was used as a reference.

The first question was about the motivation for aspiring to become a nurse: "Why did you decide to become a nurse?" The second question was "What was the most influence thing you decided to become a nurse?" This question was based on (d) perceived locus of causality, and the theory on which this perspective is based was developed by Heider [16], De Charms [17], and Deci [18]. The theory states that "If the intention to act is perceived as being caused by the individual, it is internal causality; if it is perceived as being caused by the environment, it is external causality." [1]. Furthermore, the former is intrinsic motivation, and the latter is extrinsic motivation. Therefore, to ask whether the motivation of nursing students to become nurses is intrinsically motivated by "individuals" or extrinsically motivated by "the environment," the question was "What was the most influence things you decided to become a nurse?"

The third question was "What is your goal after graduation?" This question was based on (e) the perspective of endogenous-exogenous attribution. The theory on which this perspective was based stated that "When we perform an action, it is an endogenous attribution if we recognize that there is a purpose to the action itself, and it is an exogenous attribution if we recognize that the action is a means and that there is a purpose other than performing the action" [15]. The former is intrinsic motivation, while the latter is extrinsic. "Goal" was used instead of "purpose" because a goal is "an aim to achieve a purpose," [19] and by asking about goals, the level of achievement is thought to be clarified in the behavioral dimension. Therefore, to obtain data on student characteristics, the following questions were asked: "Why did you decide to become a nurse?" "What influenced you the most to become a nurse?" and "What is your goal after graduation?"

The Japanese questions have been translated into English and Khmer using Google Translate, and the validity of the questions has been examined by the researchers. 


\section{Analysis Method}

The data obtained in the English and Khmer versions were translated into Japanese using Google Translate, and content analysis was conducted for each of the three questions according to the methodology of Berelson, B. in "Challenges to Qualitative Research" by Funashima [20]. The validity of the analysis was examined by three graduate students in the Department of Nursing and the coresearchers. The criterion of analysis was compared with the data of the study by Ichiyanagi et al. [1]

\section{Ethical Considerations}

The purpose and method of the study were explained in writing. Furthermore, written informed consent was obtained from all study participants, and no disadvantage would be suffered if the respondents refused to cooperate; personal information are handled with utmost confidentiality. Questionnaire responses were anonymous and did not record details of the respondents. This data was obtained in past classes and did not require an ethical review of our institution

\section{Data Collection Period}

Data were collected for a period of 1 week, from August 24 to August 31, 2020.

\section{Results}

The number of respondents was 34 , of which 33 were valid (11 (33\%) males and 22 (66\%) females).

The mean age was 20 years (SD: 3.2 ) (male: 20.2 years (SD: 1.8 ); female: 20.9 years (SD: 1.5)). Regarding grade levels, $12,8,9$, and 4 students were in the first, second, third, and fourth grades, respectively.

After the descriptions of 33 students were translated and converted into Japanese data, the recording units of descriptions that were highly abstract and whose meaning was unclear were eliminated. Therefore, 50 recording units for Q1, "Why did you decide to become a nurse?"; 42 recording units for $\mathrm{Q} 2$, "What influenced you most to become a nurse?"; and 43 recording units for Q3, "What are your goals after graduation?" have been analyzed. As a result of combining similar contents, a total of 19,13, and 14 subcategories for questions 1,2 , and 3 , respectively, were identified, and the categories were divided into 6 each.

Regarding Q1, “Why did you decide to become a nurse?," 14(28.6\%) of the respondents answered "I want to help my country," 13(26.5\%) "I like taking care of people," $9(18.3 \%)$ "I am attracted to nursing skills," $7(14.3 \%)$ "I want to be a pioneer in developing the nursing field in Japan," 4(8.2\%) "family's wish," and 2(4.1\%) "financial stability." Regarding Q2, "What was the most influence things you decided to become a nurse?," $12(32.5 \%)$ of the respondents answered "thinking that it is essential to help people," 7(18.9\%) "family recommendation," $6(16.2 \%)$ "love for others," 6(16.2\%) "family health problems," 5 (13.5) "thinking the need to develop nursing care," and 1(2.7\%) "Nothing." Regarding Q3, "What are your goals after graduation?" 14(38.9\%) of the respondents "want to continue studying to develop the nursing field," 7(19.4\%) "want to work in the work environment they want," $6(16.6 \%)$ "want to use what they have learned to gain experience," $5(13.5 \%)$ "want to become a nurse who plays an important role for patients," 2 (5.6\%) want "financial stability," and 2(5.6\%) "Nothing."
A comparison between Japanese nursing students and Cambodian nursing students was made. The contents of the five categories examined by Ichiyanagi et al. [1], of "intrinsic motivation," "economic aspect/independence," "past experience," "dream/aspiration," and "extrinsic motivation," were corresponded to Question 1. In the "intrinsic motivation" category, "I want to help my country" and "I like to take care of others" were categorized, and in the "economic/ independence" category, "economic stability" was categorized. In the category of "past experiences," no corresponding categories were found. "I am attracted to nursing skills" and "I want to be a pioneer in further developing the nursing field in Japan" were categorized in the "dreams and aspirations" category. "Family wishes" were categorized in the "extrinsic motivation" category.

According to a study by Ichiyanagi et al. [1], in Japan, $34.6 \%$ of nursing students responded with "intrinsic motivation," $26.4 \%$ "economic aspect/independence," 16.5\% "past experience," $12.7 \%$ "dreams and aspirations," and 9.8\% "extrinsic motivation."

Conversely, in Cambodia, 55\% of the respondents chose "intrinsic motivation," 32.7\% "dreams and aspirations," $8.2 \%$ "extrinsic motivate," $4.1 \%$ "economic aspect/independence," and $0 \%$ "past experiences."

\section{Discussion}

\section{Response to the question "Why did you decide to become a nurse?”}

The most common answer in this category was "want to help the country" (28.6\%). With this, it is believed that there is an innate motivation to help the people in Cambodia. Kage [21] stated that "the innate motivation behind the process of cognitive development is intrinsic motivation, and it functions through the dynamic interaction between the environment and the individual [21]." Additionally, after the end of the civil war, the Cambodian government urgently needed social protection for the poor and the weak, and various countries from all over the world extended aid to them [22]. Furthermore, because of the effects of the massacre of medical professionals by the Pol Pot regime, the Cambodian Ministry of Health proposed the necessity of medical personnel resources [5]. In this interaction with society, the intrinsic motivation to want to help the country may have become functional.

The second most common motivation was "I like taking care of people" (26.5\%). This motive is said to be a characteristic of interpersonal support for workers [23]. Then, "I am attracted to nursing skills" (14.3\%) and "I want to be a pioneer in further developing the nursing field in Japan (8.2\%) were also identified as intrinsic motivation. Kage [21] also stated that "If external factors increase the perception of competence, intrinsic motivation increases; if they decrease it, intrinsic motivation decreases." After the end of the civil war, with the increase in international support for Cambodia, more opportunities to compare the social status and skills of the nursing profession between Cambodia and other countries emerged. These external factors were suggested to increase the number of students who were motivated to develop the nursing field in the country and promoted intrinsic motivation.

In "family's wish" (8.2\%) and "financial stability" (8.2\%), McReynolds [24] stated that autonomous behavior is the essence of intrinsic motivation, while instrumental behavior is extrinsic motivation. These categories are considered to have been motivated by extrinsic motivation, as they aspire to become nurses 
as a means to fulfill their family's wishes and earn income. However, these extrinsic motivations were relatively low in the motivation of Cambodian nursing students.

\section{Response to the question "The most influential factors for Cambodian nursing students to become nurses"}

In this section, "thinking that it is essential to help people" (32.5\%), "love for others" (16.2\%), and "thinking the need to develop nursing care" (13.5) were mentioned. According to De Charms [17], "Human beings feel intrinsically motivated when they recognize themselves as the cause of their own actions." Therefore, Cambodian nursing students have strong intrinsic motivation to become nurses because their own thoughts influenced their actions.

Conversely, categories including "family's recommendation" and "family's health problem" suggest that "family" (75\%) is deeply related to extrinsic motivation. According to Inada [25], when faced with various risks in life, including illness and injury, people in Cambodia tend to mainly rely on their family and relatives. Moreover, Mochizuki et al. [26] stated that "Currently, nurses mainly assist doctors in the treatment of patients, and family support the life of patients in the hospital. However, in the fact, patients want nurses support for hospitalization life of patients." Despite this fact, nurses cannot support patients. Therefore, because Cambodian people cannot rely on medical personnel or the government, they tend to rely on family and relatives in case of illness or injury. In this situation, some of the nursing students were thought to become nurses to protect their family members when they face illness or injury.

\section{Response to the question "What are your goals after graduation?"}

The five categories, except for financial stability, are consistent with the goal of becoming a nurse itself, suggesting that intrinsic motivation was strong. Regarding the fact that the most common response was "want to continue studying to develop the nursing field" (38.9\%), Suzuki [27] stated that "Learning motivation is related to the orientation to acquire skills and knowledge." Therefore, the goals of acquiring skills and knowledge, including "want to develop my nursing field,"'want to use what I have learned to gain experience" (16.6\%), and "want to become a nurse who plays an important role for patients" (13.9\%), were suggested to lead to an increase in the number of students who desire to continue their studies.

\section{Comparison between Cambodian and Japanese Nursing Students}

Comparing the motivation between Cambodian and Japanese nursing students, the most common category was "intrinsic motivation" (Cambodia: 55\%, Japan: 34.6\%). However, in Japan, the motivation was "to help others" and the target was "people," while in Cambodia, the motivation was "to help the country" and the target was "the country." In both countries, the target of the motivation to be "helpful" was different. The reasons for this difference remain unclear. Hence, continuing to study the factors is necessary.

The second most common category of motivation for Japanese students was "economic aspect/independence" (26.4\%), while for Cambodia students, "economic aspect/independence" (4.1\%) was fourth. In Japan, nursing students emphasized financial rewards, including "because nurses have a stable income," and they were highly influential from extrinsic motivation and ranked it second.
Conversely, in Cambodia, household expenditure is higher than the salary of nurses (the salary per month of professional nurses is $\$ 79$ [9]; the household expenditure per month is $\$ 111$ per person [10]). Few people are motivated by financial reward and ranked it fourth.

In Japan, "past experience" (16.5\%) was the third most important reason in applying for a job, but in Cambodia, "past experience" was not answered. In Cambodia, hospitalized patients were mostly cared for by their families [24]. Therefore, it is thought that the respondents did not have many direct experiences with nurses, and this may have prevented them from expressing their reasons for applying.

"Extrinsic motivation" ranked third and fifth for Cambodia (8.2\%) and Japan $(9.8 \%)$, respectively. For Japan, the respondents answered "because of my parents or teachers." Finally, regarding "extrinsic motivation," in Japan, "parents" and "teachers" influenced the nursing students. However, in Cambodia, only "family" influenced the nursing students.

\section{Limitations}

In this study, the motives of Cambodian nursing students to become nurses have been examined. However, the number of subjects surveyed was small $(n=33)$, and the results may limit generalizability.

\section{Challenges}

To generalize the results on the motives of students to aspire to become nurses, conducting a survey that considers more respondents and various university situations is necessary. This study was conducted on a national university in an urban area; differing motives for aspiring to become nurses between urban and rural areas and between national and private universities are possible. Moreover, motivations to choose occupations may also differ between Cambodia and Japan. Further survey of these factors is needed.

\section{Conclusion}

The Cambodian nursing students were motivated to help their country, develop nursing care, and protect their families.

\section{Competing Interests}

The authors declare that they have no competing interests.

\section{Acknowledgments}

The authors would like to thank the president, faculty member in charge of international exchange, and nursing students at the National University of Cambodia for their cooperation in this study. We would also like to express our sincere gratitude to the members of the Chronic Adult Nursing Seminar who provided us with a great deal of knowledge through our daily discussions.

\section{References}

1. Ichiyanagi Y, Taniyama M, Yamazaki C, Takeuchi K, Kohama Y, et al. (2009) The actual situation and structure of the motivation of nursing students to enter and choose a career. Bulletin of Kawasaki City College of Nursing 14: 21-27.

2. International Monetary Fund (2021) World Economic Outlook database. 
3. Yamashita A (2009) Border conflict between Thailand and Cambodia. IPSHU Research Report Series, Research Center for Peace Science, Hiroshima University.

4. Amakawa A (2004) Introduction: Cambodia under ASEAN Accession: Changes in Institutions and Realities. Cambodia New Era, 539: 3-47.

5. Akiba T (2007) The state of health care in Cambodia: A study from the viewpoint of human resource development. Bulletin of Kyushu University of Health and Welfare 8: 1-8.

6. Hirakawa O, Kita E, Aoyama A (2005) Women's health issues in Cambodia during post-conflict reconstruction and development. J IntHealth 20: 7-18.

7. Japan International Cooperation Agency (2016) Report on Information Collection and Confirmation Survey on Medical Security System in Cambodia. Poverty and Economic Disparity.

8. Japanese Ministry of Justice (2020) Cambodia: Translation of Foreign Laws and Regulations, Constitution 2008

9. Japanese Ministry of Economy, Trade and Industry (2020) Basic Information on the Healthcare Market Environment in Emerging Countries. Cambodia, Healthcare.

10. World Health Organization (2014) Human Resources for Health Country Profiles Cambodia.

11. National Institute of Statistics Ministry of Planning (2018) Cambodia SocioEconomic Survey 2017. Household income and liabilities.

12. Tukada Y, Takeo E, Miyaji F, Shimizu K, Horiuchi F, et al. (2016) Nursing and midwifery education in Cambodia, and actual condition and issues of midwives who work for core provincial hospitals: through JICA training program for young leaders for Cambodia/Maternal and child health management course. Saku University Journal of Nursing Research 8: 109 $-117$.

13. Kawakami K, Utsunomiya K, Nakajima N (2019) 2030 Report on the Kagawa University Students' Dream Challenge Project: Cambodia Study Tour. Kagawa University.

14. Kamekawa J (2006) A survey study on the motivation of Japanese language teacher training course students to apply for the course: From the perspective of social and psychological factors. Review of Social Sciences 81: 1-17.

15. Sakurai S (1985) Development of a scale for measuring intrinsic and extrinsic motivation. J Psychol University of Tsukuba 7: 43-54.

16. Heider F (1958) The psychology of interpersonal relations, John Wiley \& Sons Inc.

17. DeCharms $R$ (1968) Personal Causation: The internal affective determination of behavior. New York: Academic Press.

18. Deci EL (1975) Intrinsic motivation, Plenum Press.

19. Shinmura I (1991) Dictionary of Language. Tokyo, Iwanami Shop.

20. Funashima N (2007) Challenge to qualitative research. Tokyo, Igaku Shoin 2: $40-80$

21. Kage M (1994) A critical review of studies on intrinsic motivation. Prospect of intrinsic motivation. Jpn J EduPsychol 42: 345-359.

22. Japan International Cooperation Agency (2016) Report on Information Collection and Confirmation Survey on Medical Security System in Cambodia.

23. Mori H, Nagata $\mathrm{H}$ (2007) A study of codependency tendency and its impact on nurse-patient relationship. J Health Psychol 20: 61-68.

24. McReynolds $P$ (1971) The nature and assessment of intrinsic motivation In P McReynolds, Advances in psychological assessment, Palo Alto, CF: Science and Behavior Books.

25. Inada J (2013) Modernization and the transformation of social capital in Cambodia. J Soc Cap 4: 140-141.

26. Mochizuki K, Kitayama A (2017) The role of nursing in the Kingdom of Cambodia: through a comparative study among doctors, nurses, and patients. Journal of Takasaki University of Health and Welfare 16: 135-148.

27. Suzuki T, Sakurai S (2011) Factors influencing intrinsic and extrinsic use value on learning motivation 59: 51-63. 